Review Article

\title{
Child Sexual Abuse during COVID-19 Pandemic
}

\author{
Jugal Kishore', Monica Lakhanpal Gaggar ${ }^{2}$, Jitender ${ }^{3}$ \\ ${ }^{1}$ Director Professor \& Head, Dept. of Community Medicine, Safdarjung Hospital \& VMMC, New Delhi, India. \\ ${ }^{2}$ Co-Managing partner, Gaggar \& Partners, Solicitors \& Advocates. \\ ${ }^{3}$ Program Manager Beyond Eye. \\ DOI: https://doi.org/10.24321/2454.325X.202005
}

I $\quad \begin{array}{lllll}\mathbf{N} & \mathbf{F} & \mathbf{O}\end{array}$

\section{Corresponding Author:}

Jugal Kishore, Dept. of Community Medicine, Safdarjung hospital \& VMMC, New Delhi, India.

E-mail Id:

drjugalkishore@gmail.com

Orcid Id:

https://orcid.org/0000-0001-6246-5880

How to cite this article:

Kishore J, Gaggar ML, Jitender. Child Sexual Abuse during Covid 19 Pandemic. Int J Preven Curat Comm Med 2020; 6(1): 30-36.

Date of Submission: 2020-07-08

Date of Acceptance: 2020-08-04

\section{$\begin{array}{llllllll}\mathbf{A} & \mathbf{B} & \mathbf{S} & \mathbf{T} & \mathbf{R} & \mathbf{A} & \mathbf{C} & \mathbf{T}\end{array}$}

Prevalence of child sexual abuse during epidemic and disaster is common. There are evidences that children are victims of sexual exploitation during the lockdown period. They undergo multiple physical and mental injuries which could last lifelong. In presence of law, the child sexual abuse will not stop till the society is sensitive enough for the child emotional and physical health need. Responsibility of care lies not only on parents but also on everybody because they are the asset of nation. Mass awareness program along with behaviour change communication could be better solution during the Covid-19 pandemic.

Keywords: Exploited Children, Sexual Exploitation, COVID-19, POCSO

\section{Encumbrance of Child Sexual Abuse during Coronavirus Pandemic}

Children are not surfaced out prominently during Covid 19 pandemic. But they are highly vulnerable and biggest victims of impact caused by this pandemic. Although they have least likely to be victim of fatality of Covid-19 but the crisis is having a profound effect on their overall wellbeing. All children, of all ages, and in all countries, are being affected, in particular by the socio-economic impacts and, in some cases, by preventive and control measures that may inadvertently do more harm than good. This is a universal emergency and, for some children, the impact will be lifelong. Moreover, the harmful effects of this pandemic will not be distributed equally in all countries and segments of society. But these effects are expected to be most damaging for children in the poorest countries, and in the poorest neighbourhoods, and for those in already disadvantaged or vulnerable situations.

To give a snapshot, The National Center for Missing and Exploited Children has experienced a $106 \%$ increase in global reports of suspected child sexual exploitation to its CyberTipline compared with March 2019. ${ }^{1}$

COVID-19 has led to an increasing number of children being subjected to abuse and exploitation both within and outside their homes. The Government-run helpline, CHILDLINE India reported 92,000 distress calls on child abuse and violence in the first eleven days of the nationwide lockdown. ${ }^{2}$ Loss of livelihood and economic hardships is likely to push more children out of schools and force them into child labour, further exposing them to sexual and physical abuse. According to the International Labour Organisation (ILO), children particularly girls are likely to be more burdened with household responsibilities. School closures may increase this exploitation as is evident from the other epidemics such as Ebola crisis in West Africa that witnessed spikes in child labour, neglect, sexual abuse, and teenage pregnancies. The COVID-19 pandemic has increased incidents of child abuse, child marriage, and child trafficking, and children who do not have access to safe reporting system - fall prey easily. Incidences of child 
marriage during the lockdown have already been reported in certain states as per data from UNICEF.

In India, there has been a 95\% rise in traffic searching for child sexual abuse content. ${ }^{3}$ When people are financially struggling, children tend to become more isolated and less linked to supportive networks, and the sale of children for sexual exploitation increases.

A pandemic of fear, anxiety and depression are going hand in hand with COVID-19 contagion. Children are already extrasensitive to emotional stress. In near future, a pandemic of childhood mental illness is upcoming which will include the whole disease spectrum from childhood depression, anxiety disorders, childhood obsession, pervasive developmental disorder, eating disorders to name a few.

Children living in isolated and disturbed areas and in refugee camps are at the highest risk, and as offenders usually hunt for easy victims, marginalized children are more likely to be targeted- more exposed to offenders through online gaming, the use of chat groups in apps, phishing attempts via email, unsolicited contact in social media and through less secure online educational applications.

\section{Understanding Child Sexual Abuse}

Children, while growing up, interact with various groups of people. For a better understanding of these interactions and the schematics, one can imagine the child being at the center of concentric circles. The immediate circle of the child is their parents, then close relatives, neighbours, school best friends, school peers, teachers, school staff, and so on. The usual perception of how sexual abuse happens is based on the assumption that there is always a persistent danger outside the house. However, that is not the case. Many a times the abusers are known to the child. ${ }^{4}$

Moreover, the prevalence of Coronavirus pandemic has further complicated the matters as the child's interactions are likely to be limited to the more immediate circles around them. This puts the children at an increased risk of being exposed to sexual abuse which may not be reported due to shame or stigma or because of the lack of means or access a child has to reach out to the authorities.

India still remains a country where poverty is prevalent with limited access to information and technology which makes reporting of such incidents a privilege depending on the socio-economic condition of the child. Additionally, oftentimes families do not report the incidents of child sexual abuse due to the lack of information on legal remedies.

Another important factor in child sexual abuse is the increased presence and access to internet in children's everyday routine. A child uses the internet for entertainment, social media, and educational purposes. The Internet, especially social media sites, are known to expose children to online bullying and solicitation by child predators. This creates an additional layer of threat for children as online abuse can cause mental distress to children. ${ }^{5}$ For example, recently a group of underage boys in Delhi created a group on a social media platform, Instagram, to circulate pictures of underage girls. In this incident when some girls spoke out about the incident they were subjected to threats of sexual violence. ${ }^{6}$ Such incidents show the extent and pervasiveness of online violence impacting the children, catalysing the need to deal with CSA during Covid-19. This adds more into the importance of dealing with child sexual abuse during COVID-19.

\section{Child Sexual Abuse in Presence of Exclusive and Stringent Laws}

Unfortunately, the rise in crime is most often not directly proportionate to the strictness of the law and especially not in the present case. The legislative enactments protecting us against any kind of sexual abuse or harassment have been around for more than a century, like the Indian Penal Code which was codified way back in in 1860. Further in year 2012, The Protection of Children from Sexual Offences (POCSO) $\mathrm{Act}^{7}$ came in force, which was a major legal breakthrough and gave us a definitive recognition to sexual offences against children. Just to give an overview, the POCSO Act, 2012 is a comprehensive gender-neutral law to provide for the protection of children from the offences of sexual assault, sexual harassment, and pornography and all related offences under child sexual abuse.

However, despite the most stringent laws already being in place, child sexual abuse cases are escalating on an everyday basis. Unfortunately, however, only a miniscule number get 'reported'. There is a good reason for highlighting the word 'reported' since these minuscule numbers are just the tip of the iceberg and the real problem lies in the 'unreported' cases. Thus, merely having the POCSO Act with stringent punishments including the death penalty cannot possibly be expected to act as a magic wand which could cure the evils of this crime, and certainly not when people don't even bring the crime to the notice of the authorities.

The real problem is not the lack of availability of stringent laws but the intent or willingness to use them. The question remain unanswered, can we seek a legal remedy when there is no complaint?

The real problem emanates from the "unreported" cases which are unfortunately silenced within four walls of a house by members of the family. What is further disturbing is that every fourth child is being abused by their own family member, relative, uncle etc. including blood relations.

This can be explained by giving a simple illustration for a better understanding of the subject and the issues we are confronting: 
Imagine, a mother whose child gets physically assaulted by a neighbour and gets a head or hand injury is the first person to bring the act of that neighbour in public and society at large and goes even to a police station as a first step to ensure justice and secure punishment for the accused.

But why then would the same mother whose child is sexually abused/ assaulted by the neighbour try to silence her child because of the so-called societal stigma or 'log kya kahenge'(What will people say?) attitude.

The largest part of unreported cases is where the child does not even talk to anyone, not even the immediate family and suffers in silence. Unfortunately, this behaviour again is the outcome of our own upbringing where we as parents and society people deeply engrave upon our children "Talking about Sexual Issue Is a Taboo", that is where the real problem starts.

Here, this can be explained by giving a simple illustration for better understanding:

A family is sitting together watching a movie and a sanitary napkin or condom advertisement flashes, the ladies of the house will immediately rush to the kitchen under the pretext of cooking and men will start to talk about the most innocuous things just to avoid that 30 second advertisement. The child of an impressionable age and vulnerable mind who is watching these acts of avoidance and embarrassment by their parents, immediately accepts that confronting sexual issues or anything remotely associated with it as a taboo and grow up to learn that sexual issues of any kind cannot be voiced. Leading towards an increased stigma on sex and sexuality.

\section{The Immediate Measures to be taken once the Crime has been Committed}

\section{Reporting}

Under the POCSO Act, any person who suspects that a sexual offence qua the child is likely to be committed or has gained knowledge that an offence has been committed, shall without wasting any further time report the incident to the Special Juvenile Police Unit (SJPU) or the local police. Reporting of such matter under the POCSO Act is not just a moral duty, any failure to report such an offence, is punishable with imprisonment of up to six months or fine or both. This penalty is, however, not applicable to a child less than 16 years of age.

If the case is reported by a child, it should be recorded in a language that the child can understand. If the child cannot understand the language, the police must appoint a translator or an interpreter. After reporting the police is duty bound to report the matter to the child welfare committee if the child needs urgent protection.

Media and hospitality establishments have an obligation to report the SJPU or the Local Police if they come across material which could be sexually exploitative of the child

The Ministry of Women and Child Development, for convenience and encourage reporting of such offences has recently launched Protection of Children from Sexual Offenses (POCSO) e-box in New Delhi. POCSO e-box, which is an online complaint management system for easy and direct reporting of sexual offences against children and timely action against the offenders under the POCSO Act, 2012.

\section{Medical Examination}

As per POCSO, the jurisdiction commences as soon as there is any information received by any party that a chid has been exposed to any crime under the act. Immediately upon receipt of such information, the child is required to be first of all taken for a medical examination. There are guildeines provided even with respect to the manner and mode of the medical examination that required to be conducted. Its important to note that the examniation can be conducted even if an FIR has been registered or not. While the examnaition is to be conducted at a govt medical facility, in the case of a girl child, an extra precaution has to be taken that the examiner needs to mandatoruly be a lady doctor. In order to provide whatever little comfort possible for a child faced with such a situation, its also been evisaged that the child would have his/ her parent/ someone the child trusts present at all times during the examnation. In cases where there is no such person, the hospital would be required to ensure that a lady is present with the child in any case.

Further, in case where the offence leads to any sort of physical injury, including but not limited to invasive/ penetrative acts, its imperitive for the authorities to arrange for the child to be taken to the nearest hospital or medical care facility centre for emergency medical care:

Even at that stage, precautions have been contemplated to ensure that the privacy of the child is maintained and as far as possible the child's parent/ guardian is always present. Further, in order to render the emergency medical care to the child, its been categorically provided that there would be no requirment or in fact even a demand for any legal or magisterial requisition.

Provided that where an offence has been committed is penetrative or sexual assault, the victim shall be referred to emergency medical care.

\section{Reporting Sexual offences and Injury}

The POCSO Act, seeks to provide for a holistic mechanism for addressing the various aspects that need to be dealt with post the unfortunate incident. The legislators are cognizant of the fact that the trauma for the child victim is no where close to being over with just the incident, since there are a 
number of unavoidable steps that have to be taken to bring the culprits to justice on the one hand, and simultaneously to try and confort the child in whichever way possible. Towards that end, the Act envisages various provisions to ensure that the same causes as little inconvenience and strain on the child as possible. Various exceptions have been carved out under the POCSO as comapared to the normal process to be followed under the Criminal procedure Code for the post incident investigative and judicial proceedings. The same have been done both at a practical as well as at a deeper jurisprudential level, curating the same such that the interests of the victim remains the sole priority.

The Act also casts the police in the role of child protectors during the investigative process. They are required to make whatever urgent arrangements for the child as may be required under the circumstances, whether it is arranging for medical treatment or arranging for a safe shelter for the child. Simultaneously, the poice is required to inform the Child Welfare Committee (CWC) within 24 hours of receiving the report, so that the Committee can take all further steps for ensuring the protection and best interests of the child victim.

Attention has been given to various aspects and in minute detail. For instance, the Act makes provisions for the medical examination of the child in a manner designed to cause as little distress as possible. The examination is to be carried out in the presence of the parent or other person whom the child trusts, and in the case of a female child, by a female doctor.

The spirit of the said Act lies in ensuring the welfare and protection of child and that spirit is reflected through the entire act. The judical process that's been envisaged under the Act is targetted towards minimizing the trauma and harassment and therefore even for court proceedings, there are special provisions for Special Courts, which have been have been formed to conduct child friendly in-camera trials, without revealing the identity of the child. Further the child at all times can have a parent, guardian or other trusted person present at the time of testifying and assistance of interpreters, special educators, or other professional may be taken during the trial. Very importantly, the Act seeks to eventually do way with the necessity of having the child to even appear in Court or atleast reduce the requirment of the same to bare minimum and towards that end, in a far reaching provision, the child may testify even virtually through a video-link rather than have to be physically present in the courtroom. Its important to note that this is probably the only legilsation where the entire process could be conducted online, atleast in so far as the child victim is concerned and this was in play even before the Covid times. All the aforementioned efforts however would have gone in vain had the age old age " justice delayed is justice denied" been allowed to plague this system and the Act. Therefore, this act has provided a strict timeline of having to mandatorily finish the entire case, from start to end, within a period of one year from the date the offence is reported. The act further requires the Court to assess and grant compensation to the Child victim so this money can then be used for the child's medical treatment and rehabilitation.

Lastly it is important to understand that the POCSO Act, despite being a criminal law act, has changed the contours of the jurisprudence that's to be applied while deciding the case and the manner in which the evidence etc is to be led. Simply put, while under most Acts in India, which are criminal law related, the prosecution has to necessarily prove that the crime was committed and it is only once the highest threshold of guilt is proves that the offence can be said to be committed. Under the POCSO Act, therefore, it is the accused who has to prove that he has not committed the offence and unless he is able to prove the same, he could be found guilty basis the allegatios and circumstantial evidence alone. The burden on the Complainant and victim is therefore significantly less in proving their case and the burden has now been shifted to the accued person.

\section{The lack of Awareness about the Law}

In cases of child abuse early awareness is the key and therefore it is very important to get to the root cause at the earliest. The first step towards awareness must begin with a curtain raiser event targeting the century old perception that "talking about sexual issues is Taboo".

In order to reach the masses the second most important step is to organise community sessions on this subject, every society, compound, village must have their trained representatives who in collaboration with NGO, social workers, government organisations must organise regular programmes catering to child abuse and where they are informed about the rising numbers and the reasons thereof along with the existing stringent laws and child friendly pre and post trials.

Considering that there are almost 500 million smartphones in the country, specially curated short videos can be spread throughout the system in Hindi and vernacular languages. ${ }^{8}$ Like we have dealt with issues relating to mass awareness of Covid-19, a similar exercise needs to be undertaken, taking benefit of the deep penetration of mobile phones in India. Even in the sections where smartphones are not available, a pre-recorded call can be made through the length and breadth of the country and to facilitate reporting or counselling, a single button response system can be made available wherein anyone by clicking on a numbers automatically gets connected to a counsellor or pre-recording answers to general question. 


\section{Building Mechanism at Home to prevent Child Sexual Abuse}

In such situation where child sexual abuse has become more prevalent due to COVID-19 what can be done in order to prevent and mitigate such incidents? Firstly, child sexual abuse within and outside the family as a reality needs to acknowledged. The families need to start developing safe and open spaces inside the house so children can easily express their experiences. This process is crucial, so if a child is molested or sexually assaulted, there has to be a space within the house for them to reach out to their families. In order to do so, children also need to be introduced to literature on Comprehensive Sexuality Education and child sexual abuse in the form of comic book series, information guides, educational videos etc., by organizations working with adolescents like Beyond Eye. ${ }_{9}^{9}$ Before initiating discussions on child sexual abuse there is also a need to have discussions with children on issues like growing up, body anatomy, puberty, and many more. These discussions will ease hesitation around discussing crucial issues like child sexual abuse Children need to be introduced to literature on sexuality education in the same manner as they are given books like Panchatantra, Hitopadesh, and fairy tales. This will help in normalizing the conversations on sexual abuse in later years.

Child sexual abuse adversely impacts children's mental health. Studies have shown that childhood trauma can have adverse impacts in adults. ${ }^{10}$ Which is why it is important to not blame children for abuse inflicted upon them. They need to be informed that it is not their fault and should be given adequate mental health counselling to initiate their healing process. With all these mechanisms in place, we can help in preventing child sexual abuse while also taking care of sexually abused children's mental health and their overall wellbeing.

\section{Role of Government Agencies to make Positive Interventions to Prevent Child Sexual Abuse}

Government agencies can play a crucial role in making positive interventions to prevent child sexual abuse through means like making Comprehensive Sexuality Education (CSE) mandatory in all schools. Themes like attraction, body image, desire, growing up, pleasure, puberty, violence, sexuality, etc., need to be included in children's school curriculum in order to create an open and non-judgmental environment. Sex as a taboo needs to be dealt with by introducing sex education as early as the adolescence years.

There is also a need to provide adolescent friendly visual tools such as comics, videos, and storybooks on sexuality education and child sexual abuse. These tools need to be engaging, informative, interactive, and pleasurable. One can take inspiration from television cartoon shows viewed by children. For example, Beyond Eye has developed visual tools like comic book series with characters from these famous cartoon shows. ${ }^{9}$ This method was chosen so children can relate to the cartoon characters discussing crucial issues which will help them in retaining such information. This helps in initiating a meaningful and interactive engagement with adolescents on crucial and sensitive issues like child sexual abuse.

Finally, the government agencies need to involve parents as well while providing sexuality education. They can be involved in ensuring that the household space remains safe and open for children. Through these methods we will be able to prevent child sexual abuse.

\section{Stepping up Protection of Children Against Sexual Exploitation and Abuse in Times of COVID- 19}

To mitigate the psychosocial ill-effects of COVID-19 on children and adolescents proactive and targeted interventions can be proposed. All stakeholders such as parents, doctors, psychologists, local leaders, government and non-governmental health and social organizations have important roles to play in these interventions to be successful. Concerning healthy behaviour, children have always followed their parents as the role models. Peerless parenting skills become discretely decisive while handling the children in detention. Parents need to respect their identity, free space, special need in addition to monitoring child's performance, behaviour and self-discipline.

Children are the victims of violence and psychosocial distress due to stigma related to COVID-19. At the same time, preventive and control measures if not gender sensitive then women and girls may also increase their risk of sexual exploitation, abuse and child marriage.

Some of the strategies to protect them are as follows:

- Train health, education and child services staff on COVID-19 related child protection risks, including on the prevention of sexual exploitation and abuse and how to safely report concerns

- Train first responders on how to manage disclosure of gender-based violence and collaborate with healthcare services

- Increase information sharing on referral and other support services available for children

- Engage children, particularly adolescents, in assessing how COVID-19 affects them differently to inform programming and advocacy

- Provide support to those families which are headed by child or foster families and training them to take appropriate self-care

- Provide financial and material support to the poor and families that are engaged in income generating activities 
- $\quad$ Put in place concrete measures to prevent child-family separation, and ensure support for children left alone without adequate care due to the hospitalization or death of a parent or caregiver

- Ensure the protection of all children is given the utmost consideration in disease control measures

- Make Comprehensive Sexuality Education as part of school curriculum from the class $6^{\text {th }}$.

Online child sexual exploitation is a complex crime that requires multiprong strategy involving legal, medical, social, national and international bodies for effective comprehensive program. All governments can initiate following actions during Covid-19 pandemic:

- Helplines for children to report and getting all types of support

- Availability of professional police, social and health staff to respond quickly and effectively

- Establishment of child friendly justice system for quick prosecution of perpetrators

- Adequate infrastructure, legal system and resources to deal with long term support for survivals and those at risk and also protection of online users and safety of products

- Awareness programs involving corporate organizations to educate abut online harms and development of humanized and protected products.

\section{Awareness Program on Child Sexual Abuse}

This is an unprecedented crisis and it presents unprecedented risks to the rights and safety and development of the world's children. This can be mitigated and resolved by concerted efforts in the field of information, solidarity and action involving all stakeholders. Present pandemic of COVID-19 has affected children on three fronts- infection from the corona virus; the socioeconomic impacts of lockdown, isolation, treatment etc; and long-term effects of delayed implementation of the Sustainable Development Goals. However, at the local level many interventions can be initiated to avoid child sexual abuse.

Friendly interaction and communication between parents and children may help soothing their pandemic-related anxieties and engaging children in household activities so that family relations will re-vitalize and psychologically buttressed.

There is need of awareness program which should include following components:

- Understanding preventive and control measures required for COVID-19 and basic behaviour change for healthy practices

- Understanding emotional needs and providing psychosocial Support for Children during COVID-19
- Children should able to learn to deal with stressful conditions

- Parents and family members should able to recognized the signs of distress which required professional help

- Parents should negotiate with children for screen time and physical activities

- Open access of parents on online or offline games and apps so that they can have information who are contacting and playing with them. Children should use strong password which is difficult to be hijacked.

- Use of webcams should be restricted to online family get together and online classes

- Geolocation of the devise may be turned off to avoid any victimization

- Children surroundings and neighbourhood should be trustworthy

We have a chance to not only defeat this pandemic, but to transform the way we nurture and invest in the young generation. But we have to act now, we have to act decisively, and at very large scale. This is not a gradual issue, it is a clarion call for the world's children, the world's future.

\section{Conflicts of Interest: None}

\section{References}

1. https://www.missingkids.org/gethelpnow/cybertipline (Accessed on 30.6.20).

2. https://www.equalitynow.org/covid_19_online_ exploitation (Accessed on 30.6.2020).

3. https://www.thehindu.com/news/national/ coronavirus-lockdown-govt-helpline-receives92000-calls-on-child-abuse-and-violence-in-11-days/ article31287468.ece (Accessed on 30.6.20).

4. Ravi R. 90\% Of Abusers Are Known To Victim: How This NGO Is Prepping Families To Fight Child Sexual Abuse. The Logical Indian 2020. Link:https:// thelogicalindian.com/exclusive/lockdown-child-sexualabuse-cases-20852.

5. Kanna R. Most online content on child sexual abuse from India. The Hindu, April $18^{\text {th }}, 2020$, accessed on June $22^{\text {nd }}, 2020$, https://www.thehindu.com/news/ national/most-online-content-on-child-sexual-abusefrom-india/article31377784.ece.

6. Ravi S. Bois Locker Room, a reflection of an existing mindset. The Hindu, May $21^{\text {st }}, 2020$, accessed on June $22^{\text {nd }}, 2020$, https://www.thehindu.com/news/cities/ Delhi/bois-locker-room-a-reflectionof-an-existingmindset/article31638044.ece.

7. Government of India. The Protection of Children from Sexual Offences (Amend) 2012. Ministry of Women and Child Development.

8. KPMG-FICCI. Indian Media and Entertaiment Industry. The future : Now streams. https://assets.kpmg/ 
content/dam/kpmg/in/pdf/2016/12/The-Future-nowstreaming.pdf.

9. Beyond Eye: http://beyondeye.org/ Has created a comic series depicting child sexual abuse as an aid to the facilitator to have conversation on this issue.

10. De Bellis MD and Zisk A. The biological effects of childhood trauma. Child and Adolescent Psychiatric Clinics 2014; 23(2): 185-222. 